\title{
Distress and delay associated with urinary incontinence, frequency, and urgency in women
}

\author{
P A Norton, L D MacDonald, P M Sedgwick, S L Stanton
}

Departments of Obstetrics and Gynaecology

(Urodynamic Unit), St

George's and St James's

Hospitals, London

P A Norton, MD, honorary

clinical research fellow

S L Stanton, FRCOG,

consultant and honorary senior

lecturer

Clinical Epidemiology and

Social Medicine, St

George's Hospital Medical

School, London

L D MacDonald, PHD,

lecturer

P M Sedgwick, BSC,

statistical assistan

Correspondence to: $\mathrm{Mr}$

S L Stanton, Urodynamic

Unit, Department of

Obstetrics and Gynaecology,

St George's Hospital,

Cranmer Terrace, London

SW17 ORE.
It is ironic that though many personal topics may be openly discussed with patients or in the media, urological symptoms are still largely avoided. Yet urinary complaints are common among women, although exact prevalence is difficult to estimate because various researchers use different definitions of severity and patients have different thresholds for complaint. Nemir and Middleton ${ }^{1}$ found occasional stress incontinence in half of the premenopausal women they studied, and Brocklehurst ${ }^{2}$ estimated the prevalence of urgency, frequency, and nocturia in elderly women to be $60 \%$. Using stricter criteria, Yarnell et al found that $3-7 \%$ of women in the general population complained of "significant" urinary incontinence."

It seems that patients who present to their doctor complaining of various urinary symptoms, from occasional episodes to constant leakage, share one common factor: the problem has become so personally worrying that the patient is compelled to seek medical advice. Thomas et al found that only a third of women complaining of moderate or severe incontinence were receiving medical care or help from the social services. ${ }^{4}$ In the study by Yarnell et al of the women who reported that urinary symptoms interfered with social or domestic life, only half had sought medical advice. ${ }^{3}$ Thus patients with urinary symptoms who seek medical advice represent only the tip of the iceberg, and many who are troubled by their urinary complaints may delay seeking treatment. Although such delay is a common clinical impression, it has not been previously investigated.

The purpose of this study was to examine initial delay and reasons for delay in seeking treatment among women who were ultimately referred to a urodynamic clinic. Since delay might be justified if symptoms are not unduly troublesome to the woman restriction of activities and feelings of stigma were also assessed.

TABLE I-Delay in seeking medical advice by age group and by marital state. Figures are numbers (and percentages)

\begin{tabular}{|c|c|c|c|c|c|c|c|}
\hline \multirow[b]{2}{*}{ Delay (years) } & \multicolumn{4}{|c|}{ Age (years) } & \multicolumn{2}{|c|}{ Marital state } & \multirow[b]{2}{*}{ Total } \\
\hline & $\leqslant 35$ & $36-49$ & $50-64$ & $\geqslant 65$ & Married & Unmarried & \\
\hline $\begin{array}{l}\leqslant 1 \\
1-5 \\
\geqslant 5\end{array}$ & $\begin{aligned} 18 & (45) \\
14 & (35) \\
8 & (20)\end{aligned}$ & $\begin{array}{ll}28 & (44) \\
22 & (34) \\
14 & (22)\end{array}$ & $\begin{array}{ll}17 & (29) \\
27 & (46) \\
15 & (25)\end{array}$ & $\begin{array}{rr}19 & (53) \\
3 & (8) \\
14 & (39)\end{array}$ & $\begin{array}{ll}52 & (36) \\
58 & (40) \\
35 & (24)\end{array}$ & $\begin{array}{rr}30 & (55) \\
8 & (15) \\
16 & (30)\end{array}$ & $\begin{array}{ll}82 & (41) \\
66 & (33) \\
51 & (26)\end{array}$ \\
\hline Total & $40(100)$ & $\begin{array}{r}64(100) \\
\chi^{2}=16 \cdot 5, d\end{array}$ & $\begin{array}{c}59(100) \\
6, p<0.01\end{array}$ & $36(100)$ & $\begin{array}{c}145(100) \\
\chi^{2}=11 \cdot 7,\end{array}$ & $\begin{aligned} & 54(100) \\
= & 2, \mathrm{p}<0.01\end{aligned}$ & $199(100)$ \\
\hline
\end{tabular}

Note: Percentages are rounded. Two women could not recall the length of delay

TABLE II -Reasons for delay in seeking medical advice in 162 women by type of worst symptom and by age group. Figures are numbers (and percentages)

\begin{tabular}{|c|c|c|c|c|}
\hline Most common responses ${ }^{\star}$ & $\begin{array}{l}\text { Hoped symptom } \\
\text { would get better }\end{array}$ & $\begin{array}{l}\text { Too embarrassed } \\
\text { to talk to } \\
\text { general practitioner }\end{array}$ & $\begin{array}{l}\text { Afraid of needing } \\
\text { operation }\end{array}$ & $\begin{array}{l}\text { Thought symptoms } \\
\text { were normal }\end{array}$ \\
\hline \multicolumn{5}{|l|}{ Type of worst symptom $\dagger$ : } \\
\hline Incontinent $(n=111)$ & $73(66)$ & $52(47)$ & $20(18)$ & $12(11)$ \\
\hline \multirow[t]{2}{*}{ Continent $(n=43)$} & $34(79)$ & $15(35)$ & $8(19)$ & $12(28)$ \\
\hline & NS & NS & NS & $\chi^{2}=6.7, \mathrm{df}=1, \mathrm{p}<0.01$ \\
\hline \multicolumn{5}{|l|}{ Age group: } \\
\hline$\leqslant 35(n=31)$ & $21(68)$ & $14(45)$ & $2(6)$ & $6(19)$ \\
\hline $36-49(n=57)$ & $41(72)$ & $20(35)$ & $15(26)$ & $7(12)$ \\
\hline $50-64(n=47)$ & $36(77)$ & $21(45)$ & $5(11)$ & $9(19)$ \\
\hline \multirow[t]{2}{*}{$\geqslant 65(n=27)$} & $14(52)$ & $13(48)$ & $7(26)$ & $5(19)$ \\
\hline & NS & NS & $\chi^{2}=8.4, d f=3, p<0.05$ & NS \\
\hline
\end{tabular}

*Multiple responses were possible.

tEight women were not classified for this analysis.

\section{Patients and methods}

The study was carried out among 201 successive women aged 16 and over who were undergoing initial assessment at urodynamic clinics held at St George's and St James's Hospitals, London. A total of $121(60 \%)$ had been referred directly by their general practitioner and the rest by other specialists. Patients were excluded from the study only if they were demented, which was determined by administering Hodkinson's dementia scales.'

The research instrument was a self completed questionnaire that combined closed and open responses, which was followed by a brief interview conducted by PAN. Questions were generated from responses to a previous pilot study that was carried out with 100 successive patients. The final questionnaire included details about worst symptoms, associated symptoms, and interference with daily activities. Emotional and social consequences of urinary symptoms were assessed using a self rated stigma measure. "Worst" symptom was defined as the one that the patient identified as being the most troublesome. Patients were asked about duration of symptoms, time spent under the care of a general practitioner, and reasons for waiting before going to the doctor. Actual delay was measured from the time symptoms became troublesome to the time that initial medical advice was sought. Results were analysed by age, marital and employment state, and type of worst symptom, using a standard statistical package, and tested for statistical significance using the $\chi^{2}$ test. All associations reported are statistically significant $(\mathrm{p}<0.05)$ unless otherwise stated

\section{Results}

All 201 patients studied were women, and their ages ranged from 16 to 86 years (mean 49 years). Thus half the women in the study were in the premenopausal age group. Three quarters were married or living with a partner, and $92(46 \%)$ were in paid employment outside the home.

Two thirds (133) reported incontinence as the worst symptom. Of these, $76(57 \%)$ complained primarily of stress incontinence and $57(43 \%)$ of urge incontinence. The rest $(68 ; 34 \%)$ were continent but complained of urgency $(22 ; 32 \%)$, frequency and nocturia $(41 ; 60 \%)$, or voiding difficulties (five; $8 \%$ ). Some of those categorised as continent also suffered occasional, lesser symptoms of incontinence.

Associations among age, marital and employment state, and type of worst symptoms were examined. In women under 35 frequency was the most prevalent symptom, while stress incontinence was most often reported by women aged 35-49. Those aged 50-64 had mixed complaints, and urge incontinence was most prevalent among women of 65 and over. Overall, the prevalence of incontinence rose with increasing age. There were no significant associations observed among worst symptom, marital state, and employment state.

\section{DELAY}

Table I shows the delay from the time the symptoms first became troublesome until a general practitioner's advice was sought. Two fifths of women consulted a doctor within one year of symptoms becoming troublesome. A third delayed for one to five years, and a quarter waited for more than five years. Delay was 
TABLE III - Interference with daily activities and effects of stigma by type of worst symptom, age, marital state, and employment. Figures are numbers (and percentages)

\begin{tabular}{|c|c|c|c|c|c|c|c|c|c|c|c|c|c|c|c|}
\hline \multirow[b]{2}{*}{ Responses* } & \multicolumn{2}{|c|}{ Worst symptom } & \multirow[b]{2}{*}{$\chi^{2}$ test, $\mathrm{df}=1$} & \multicolumn{4}{|c|}{ Age (years) } & \multirow[b]{2}{*}{$\chi^{2}$ test, $\mathrm{df}=3$} & \multicolumn{2}{|c|}{ Marital state } & \multirow[b]{2}{*}{$\chi^{2}$ test, $\mathrm{df}=1$} & \multicolumn{2}{|c|}{ Employment } & \multirow[b]{2}{*}{$\chi^{2}$ test, $\mathrm{df}=1$} & \multirow[b]{2}{*}{ Totalt } \\
\hline & Incontinent & Continent & & $\leqslant 35$ & $36-49$ & $50-64$ & $\geqslant 65$ & & Married & Unmarried & & Home & Work & & \\
\hline \multicolumn{16}{|l|}{ Interference: } \\
\hline Wear pads daily & $111(85)$ & $23(40)$ & $\chi^{2}=41, p<0.001$ & $24(63)$ & $48(74)$ & $43(73)$ & $27(77)$ & NS & $107(74)$ & $35(66)$ & NS & $79(71)$ & $63(73)$ & NS & $197(72)$ \\
\hline Restrict fluid intake & $92(70)$ & 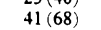 & $1, p<0$ & $26(67)$ & $52(80)$ & $36(60)$ & $25(69)$ & NS & & & $\mathrm{N}$ & & & & 0) \\
\hline $\mathrm{y}$ from home & $79(60)$ & $35(58)$ & $\mathrm{N}$ & $21(53)$ & $34(52)$ & $36(60)$ & $29(81)$ & $x^{2}=8.8, p<0.01$ & 80 & $40(73)$ & $\chi^{i}=5.3, p<0.05$ & 73 & 47 & & $201(60)$ \\
\hline Work & $73(58)$ & $25(45)$ & NS & $29(33)$ & $35(56)$. & $26(46)$ & $11(35)$ & $\chi^{2}=11.06, p<0.01$ & $74(54)$ & $27(52)$ & NS & $47(46)$ & $54(61)$ & $\chi^{2}=4.4, p<0.05$ & $190(53)$ \\
\hline Avoid public transport & $58(45)$ & $29(48)$ & NS & $16(40)$ & $26(41)$ & $26(44)$ & $23(66)$ & NS & $63(45)$ & $28(51)$ & NS & $61(55)$ & $30(35)$ & $\hat{\chi^{2}}=7 \cdot 8, p<0.01$ & $199(48)$ \\
\hline Cannot lift or carry & $66(51)$ & $18(32)$ & $\chi^{2}=6 \cdot 1, p<0.01$ & $16(41)$ & $30(48)$ & $25(43)$ & $16(44)$ & $\mathrm{v}$ & $63(44)$ & $24(45)$ & $\mathrm{N}$ & $52(47)$ & $35(42)$ & 3 & $195(45)$ \\
\hline \\
\hline $\begin{array}{l}\text { Feel odd and different } \\
\text { Feel less autrative }\end{array}$ & $66(50)$ & $\begin{array}{l}26(44) \\
16(28)\end{array}$ & $x^{2}=6.4 .0<0.01$ & $17(44)$ & $\begin{array}{l}28(43) \\
29(47)\end{array}$ & $\begin{array}{l}31(52) \\
23(38)\end{array}$ & $\begin{array}{l}20(56) \\
10(29)\end{array}$ & NS & $\begin{array}{l}67(46) \\
56(29)\end{array}$ & $29(53)$ & NS & $54(48)$ & $42(48)$ & NS & $199(48)$ \\
\hline Avoid sexu & $52(40)$ & $\begin{array}{l}10(28) \\
24(41)\end{array}$ & $\begin{array}{c}x=0.4, p<0.01 \\
\text { NS }\end{array}$ & $23(59)$ & $26(42)$ & $\begin{array}{l}23(38) \\
24(41)\end{array}$ & $\begin{array}{r}10(29) \\
4(11)\end{array}$ & $\chi^{2}=17.9, \mathrm{p}<0.001$ & $\begin{array}{l}36(29) \\
63(45)\end{array}$ & $\begin{array}{l}23(42) \\
13(24)\end{array}$ & $\chi^{2}=6.9, \mathrm{NS}<0.001$ & $\begin{array}{l}41(37) \\
35(32)\end{array}$ & $\begin{array}{l}38(44) \\
42(44)\end{array}$ & $\begin{array}{c}N S \\
\chi^{2}=5.9, p<0.05\end{array}$ & $\begin{array}{l}196(40) \\
197(40)\end{array}$ \\
\hline Avoid & $32(25)$ & $16(27)$ & NS & $11(28)$ & $10(16)$ & $16(27)$ & $13(36)$ & NS & $27(19)$ & $23(42)$ & $\hat{x}^{2}=11 \cdot 2, p$ & $29(26)$ & $21(24)$ & NS & $199(25)$ \\
\hline Others avoid patient & $17(8)$ & $3(5)$ & NS & $2(5)$ & $1(2)$ & $7(12)$ & $5(14)$ & NS & $11(8)$ & $4(7)$ & 3 & $12(11)$ & $3(3)$ & $\chi^{2}=3.7, p<0.05$ & 199 (8) \\
\hline
\end{tabular}

* Multiple responses were possible.

significantly associated with age. Elderly women had a divergent pattern of presentation, with half seeking help within a year and two fifths waiting more than five years. The proportion of women aged 65 and over who delayed more than five years was twice that of women aged under 35 years. Delay was also associated with marital state. A higher proportion of unmarried than married women sought advice within one year, while married women were much more likely to delay one to five years. Worst symptom and employment state were not significantly associated with delay.

When asked why they waited (table II) both continent and incontinent patients most often said that they hoped symptoms would get better on their own, while two fifths of patients overall said that they were too embarrassed to discuss the problem with their general practitioner. But a higher proportion of continent women also delayed because they had thought their symptoms were normal, while a higher proportion of incontinent women also delayed because they were too embarrassed to discuss their problem with their general practitioner, although this difference was not significant. Elderly women delayed for fear of surgery more often than women in other age groups but otherwise did not differ significantly from younger women. Employment and marital state had no significant effect on reason for delay.

Most of the patients in the study thought that they had been referred for specialist assessment within a reasonable period, the average time spent in general practitioner care being just over three months. Married women were referred more quickly than unmarried women ( $74 \% v 60 \%$ within six months). Age, employment state, and worst symptom were not significantly associated with time spent in the general practitioner's care.

\section{DISTRESS}

Women were asked the extent to which their urinary symptoms interfered with their daily activities (table III). The most frequently reported restrictions were avoidance of fluids and the need to wear pads, the last mainly reported by incontinent patients. Incontinent women were also less able to carry or lift as part of their daily activities. Those who avoided going far from home were mainly elderly or unmarried. Elderly women and women at home avoided public transport most often. More than half of the patients said that their urinary symptoms were affecting their work, and this was associated most often with younger women and those in employment outside the home.

Table III also shows the effects of stigma associated with urinary symptoms. Nearly half the patients reported feeling odd and different from other people because of their bladder problems. Two fifths felt less attractive, especially those with incontinence as the worst symptom. A quarter avoided other people because of their urinary symptoms, and this was reported more often by unmarried than married women. Feelings of being avoided by others increased with increas- ing age and were reported more often by women at home. Most patients reported that they avoided sexual intercourse. Two thirds of these attributed sexual avoidance directly to their urinary problems. This aspect was particularly notable among women under 65 and among those who were unmarried. There were no significant associations between sexual activity, worst symptom, or employment.

\section{Discussion}

Although the results of several studies have shown much distress associated with urinary complaints, ${ }^{348}$ there is little information on delay in seeking medical treatment. Despite reporting considerable restriction of activity and feelings of stigma most of our patients had delayed seeking medical advice for troublesome symptoms for more than a year. The patients in the study were women who had come to medical attention. In regard to patients who have troublesome urinary symptoms but have not yet sought medical attention it may be hypothesised that they follow this same pattern of delay while suffering considerable distress.

We found that the length of delay was not directly correlated with reported distress. Reasons for delay reflected lack of information, such as acceptance of symptoms as normal and fear that surgery was the only treatment available. Also, Blaxter found that women whose explanations of symptoms lay outside clinical categories might refrain from seeking medical help, and this might have been the case among these patients. Much of the delay, however, was related to embarrassment and reluctance to discuss the problem with their general practitioner. Patients were not asked whether their general practitioner was a man or a woman. Nevertheless, many women might have found it easier to speak to a woman doctor about stigmatising medical conditions, but $79 \%$ of general practitioners in the United Kingdom are men.

Remarkably patients with the same symptoms and same reported interference with daily life waited appreciably different periods of time before seeking treatment. Wyman et al found that a patient's perception of the psychosocial impact of urinary symptoms was not correlated with objective severity of symptoms. ${ }^{8}$ The sense of stigma (shame and embarrassment) may override other aspects of distress to lead to delay in seeking help. Surprisingly several factors did not lead to early consultation - that is, incontinent women delayed as long as continent women, and employed women delayed as long as those at home and not employed. Elderly women comprised the highest proportion, delaying more than five years. Yet considerable restriction was reported by elderly women as well as by women at home. But feelings of stigma, reflected in self assessed isolation and low self esteem, were high among all groups; the finding that nearly half of all patients reported feeling odd and different from others because of their urinary symptoms is sobering.

There is no evidence that early medical intervention 
is more effective in treating the complaints reported here. Early treatment, however, might encompass more self help or behavioural therapies, reduce time spent suffering distress, and increase patients' confidence in their doctor.

The results of this study suggest the following:

(1) Women need to be informed that help for many urinary complaints is available and that many symptoms can be alleviated if not eradicated without surgery. Patients need accurate and current information both to reduce the stigma attached to these complaints and to open lines of communication with their health care providers.

(2) General practitioners should be encouraged to elicit urinary complaints from women since most patients with these problems are unable to bring the subject up themselves. There are many referral centres for assessment and urodynamic testing, and specially trained incontinence advisers work in most health districts. Such ancillary services are crucial as many of these patients are virtually housebound because of their problems.

(3) Lastly, all medical workers who care for patients with urinary disorders need to continue to be sensitive to the great emotional and social distress associated with these complaints.

1 Nemir A, Middleton R. Stress incontinence in young nulliparous women. Am $\mathcal{Y}$ Obstet Gynecol 1954;68:1166-70.

2 Brocklehurst J. Aging of the human bladder. Geriatrics 1972;27:154-61.

Yarnell J, Voyle G, Richards C, Stephenson T. The prevalence and severity of urinary incontinence in women. $\mathcal{F}$ E pidemiol Community Health 1981;35:71-4. Thomas T, Plymat K, Blannin J, Meade T. Prevalence of urinary incontinence. BrMed f 1980;281:1243-5.

5 Hodkinson H. Evaluation of a mental test screen for assessment of mental impairment in the elderly. Age Ageing 1972;1:233-8.

6 MacDonald LD, Anderson HR. Stigma in patients with rectal cancer: a community study. I Epidemiol Community Health 1984;38:284-90.

7 Blaxter $M$. The causes of disease: women talking. Soc Sci Med 1983;17:59-69.

8 Wyman J, Harkins S, Choi S, Taylor J, Fantl J. Psychosocial impact of urinary incontinence in women. Obstet Gynecol 1987;70:378-80.

(Accepted 22 August 1988

\section{Correction: How to choose a general practice computing system: comparison of commercial packages}

We regret that, owing to poor printing, large areas of the table in this article by Angela Daniels and Angela Coulter (1 October, $p 838$ ) did not come out clearly. We are therefore reproducing it again.

General practitioners' guide to practice computer systems. (Although we have made every effort to check these details, systems are constantly being developed and improved and we cannot guarantee that there are no omissions)

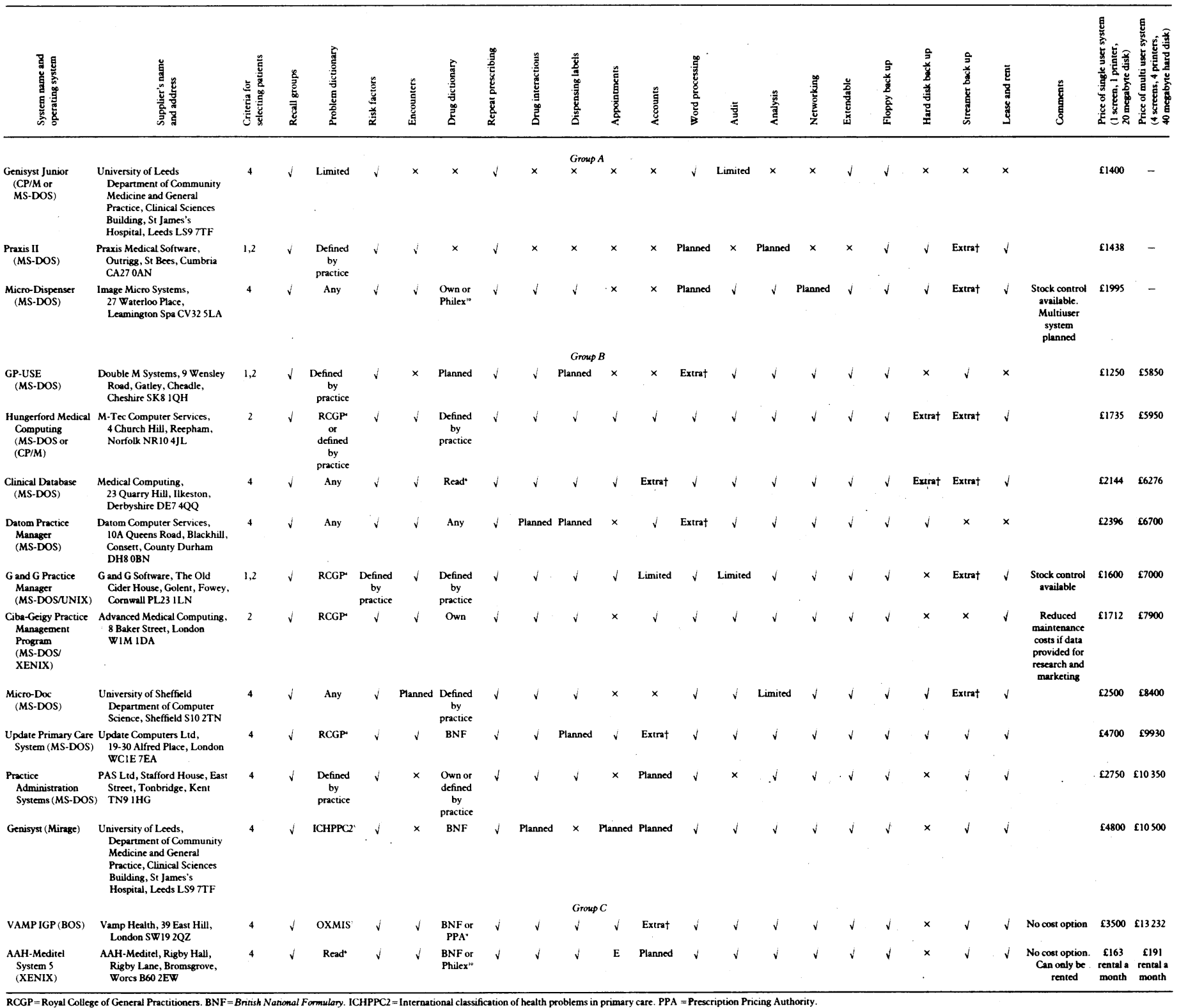

RCGP $=$ Royal College of General Practitioners. BNF $=$ British National Formulary. ICHPPC2 $=$ International classification of health problems in primary care. PPA $=$ Prescription Pricing Authority.

$* 1=$ By patient number: $2=t$
+ Available at extra cost. 